\title{
CONCEPÇÕES DE ESTADO E POLÍTICA EDUCACIONAL: UMA ANÁLISE COMPARATIVA A PARTIR DAS PERSPECTIVAS EPISTEMOLÓGICAS
}

\author{
Solange Toldo Soares (Pedagoga e Mestre em Educação pela Universidade Federal do \\ Paraná. Cursando Doutorado em Educação pela Universidade Estadual de Ponta Grossa. \\ Professora no Departamento de Pedagogia da Unicentro/ Irati)
}

\section{RESUMO}

Escolhemos a cartografia social como metodologia de nossa pesquisa, que buscou comparar as perspectivas analíticas explicitadas pelos pesquisadores com as concepções de Estado e Política Educacional em suas análises. Mapeamos, assim, na amostra analisada, referente ao campo de estudo da Política Educacional, que as perspectivas epistemológicas mais recorrentes foram o marxismo, estruturalismo, pós-estruturalismo e pluralismo, porém nem sempre essas apareceram de forma explícita nos trabalhos, o que nos levou a inferir que o debate epistemológico no campo de estudo da Política Educacional, no Brasil, é urgente e necessário. Ademais, de forma plural, procuramos apresentar as concepções dos autores sobre Estado e Política Educacional e a possível relação com a epistemologia utilizada. Isso nos fez concluir que a pesquisa em Política Educacional depende de expressões mais veementes sobre as concepções de Política Educacional e Estado, seja qual for a teoria e epistemologia adotadas pelo pesquisador, visto que seus conceitos poderiam trazer mais reflexões no que diz respeito às mediações necessárias para a efetivação do direito à educação no país, pois, sem rigor conceitual, podemos deixar de ter uma pesquisa politicamente comprometida.

Palavras-chave: Meta-análise. Cartografia Social. Política Educacional.

\begin{abstract}
Social cartography was the research methodology of choice in our research that sought to compare the analytical perspective made explicit by the researchers with the conceptions of education in State and Politics in their analyses. In the sample analysed, referred to the field of the study on educational politics, the mapping performed was on more recurrent epistemological perspectives, which were Marxism, structuralism, post-structuralism and pluralism. However, these perspectives did not always appear explicitly in the studies, which led us to conclude that the epistemological debate in the field of education in politics in Brazil is urgent and necessary. In addition, we tried to demonstrate the authors' concepts about the education in State and Politics, in a plural way, and the possible relationship with the epistemology used. Therefore, we came to the conclusion that the education in political research depends on more vehement expressions on the conceptions of the education in Politics and State, whatever the theory and epistemology adopted by the researcher, because these concepts could bring more reflections regarding the mediations required for the application of the right to education in the country, because without conceptual rigour it may lead to a less politically engaged research.
\end{abstract}

Keywords: Meta-analysis. Social Cartography. Education in Politics. 


\section{INTRODUÇÃO}

Esta proposição tem como objetivo comparar as perspectivas analíticas ${ }^{1}$ explicitadas pelos pesquisadores com as concepções de Estado e Política Educacional em suas análises. Para a concretização de nosso objetivo de pesquisa, escolhemos uma amostra $^{2}$ no âmbito da pós-graduação em Educação no Paraná/BR, especificamente as teses e dissertações defendidas entre 2010-2012 na linha de pesquisa "Política Educacional", registradas no documento "Teses e Dissertações" dos Cadernos de Indicadores da CAPES (2015), e, por meio de meta-análise $e^{3}$, buscamos problematizar as diferentes formas de interpretar a Política Educacional.

Escolhemos a cartografia social como metodologia de nossa pesquisa porque possibilita "[...] uma nova forma de olhar o mundo, e, por conseguinte, uma nova face do mundo para onde se olha" (PAULSTON, 2001, p. 224), portanto, procuramos mostrar as várias faces das teorias utilizadas pelos pesquisadores com o intuito de construir um debate comparativo.

O texto foi organizado, primeiramente, apresentando o contexto do Ensino Superior brasileiro para, assim, refletir sobre como estão estruturados os modos de produção de conhecimento e o debate epistemológico em Política Educacional na universidade brasileira. Por conseguinte, apresentamos o contexto do debate epistemológico no campo acadêmico da política educacional no Brasil e finalizamos com os resultados de nossa meta-análise, então, apontando a comparação entre perspectivas analíticas e as concepções de Estado e Política Educacional.

\section{OS MODOS DE PRODUÇÃO DE CONHECIMENTO E O DEBATE EPISTEMOLÓGICO EM POLÍTICA EDUCACIONAL NA UNIVERSIDADE BRASILEIRA}

A Constituição brasileira de 1988 conceitua o termo universidade vinculado à indissociabilidade do tripé ensino-pesquisa-extensão. Inicialmente, podemos afirmar que, até os anos de 1990, a universidade tinha uma orientação voltada para a pesquisa básica, o que Cury (2014) denominou "orientação humboldtiana", pois, quando Humboldt 
conceituou "universidade", em 1808, em Berlim, pressupôs que a atividade própria da universidade era a produção da ciência por meio da pesquisa.

Depois de 1990, mudanças passaram a atingir o perfil da universidade brasileira e o Ensino Superior de uma maneira geral. Houve um deslocamento do papel do Estado para um tipo de terceirização em relação à sociedade civil, então, adotando-se um modelo de universidade pragmática (CURY, 2014). Esse pragmatismo reza que o conhecimento que é descoberto na universidade precisa ser aplicado à sociedade, e, conforme aponta Cury (2014), isso leva a um novo fenômeno no Ensino Superior após 1990, principalmente na universidade pública, ou seja, ao "empreendedorismo acadêmico", pois,

[...] a urgência em articular a universidade com a transferência de conhecimentos inovadores para o setor produtivo por meio de escritórios especializados em tecnologia indica uma busca alternativa de fonte de recursos que não a advinda dos fundos públicos. Tal deslocamento implicaria na redefinição do conhecimento de modo que este se intencionaria mais em função do mercado do que para os interesses mais amplos sediados na pesquisa básica e no conhecimento crítico-contextual. (CURY, 2014, p. 623).

À luz do conceito que define universidade a partir da Constituição de 1988, as atividades dos professores nas universidades públicas, principalmente daqueles que trabalham no regime de Dedicação Exclusiva (DE), pressupõem ensino, pesquisa e extensão de maneira articulada; nesse contexto, a extensão é entendida como aquela atividade que estende para a comunidade os conhecimentos descobertos na universidade por meio da pesquisa. Com o chamado empreendedorismo acadêmico, são firmadas parcerias entre universidades e empresas, e, desse modo, a universidade presta serviço para estas e recebe financiamento oriundo de interesses privados.

Isso abre espaço para um deslocamento do real significado da pesquisa e da extensão na universidade pública brasileira, pois, estando a serviço do mercado, afirma Cury (2014), a universidade pública deixa de atender interesses mais amplos próprios da pesquisa básica. Ao observar esse fenômeno, podemos fazer uma relação com a promiscuidade entre o público e o privado, apontada por Saviani (2010), que destaca que a organização educacional no Brasil misturou, por muito tempo, os interesses públicos e privados, porém sobrepondo os interesses privados aos interesses públicos na história da educação brasileira.

Há uma questão ideológica que envolve o fato de que novas fronteiras entre público e privado têm sido abertas no Brasil, em que o Estado tem um caráter normativo, regulador e avaliador (FERREIRA; OLIVEIRA, 2009). Cada vez mais, por conseguinte, a 
tendência é que o Estado terceirize suas obrigações para a iniciativa privada por meio de convênios, o que gera um deslocamento dos direitos do cidadão para oferta de serviços privados.

Outros fatos marcam a promiscuidade público-privada no Ensino Superior brasileiro, como, por exemplo, a legislação possibilitar que o Ensino Superior, deslocado da figura da universidade, priorize o ensino. Assim, na oferta privada, nos institutos superiores, nas faculdades isoladas e mesmo nos centros universitários, não há obrigatoriedade da articulação entre ensino, pesquisa e extensão, a prioridade é o ensino no seu modelo mais tradicional de "transmissão" de conhecimento (CURY, 2014). Como podemos verificar nas metas do Plano Nacional, existe uma grande preocupação do Estado brasileiro em aumentar o acesso ao Ensino Superior, com prioridade para o ensino:

Meta 12: Elevar a taxa de matrícula na educação superior para cinquenta por cento e a taxa líquida para trinta e três por cento da população de dezoito a vinte e quatro anos, assegurando a qualidade da oferta. [...]

Meta 13: Elevar a qualidade da educação superior pela ampliação da atuação de mestres e doutores nas instituições de educação superior para setenta e cinco por cento, no mínimo, do corpo docente em efetivo exercício, sendo, do total, trinta e cinco por cento doutores. [...]

Meta 14: Elevar gradualmente o número de matrículas na pós-graduação stricto sensu, de modo a atingir a titulação anual de sessenta mil mestres e vinte e cinco mil doutores. [...]

Meta 15: Garantir, em regime de colaboração entre a União, os Estados, o distrito Federal e os Municípios, no prazo de 1 (um) ano de vigência deste PNE, política nacional de formação dos profissionais da educação de que tratam os incisos I, II e III do caput do art. 61 da Lei no 9394, de 20 de dezembro de 1996, assegurando que todos os professores e as professoras da educação básica possuam formação específica de nível superior, obtida em curso de licenciatura na área do conhecimento em que atuam. [...] (BRASIL, 2010, apud CURY, 2014, p. 611-616).

As estratégias para cumprir essas metas pressupõem grande vinculação com a iniciativa privada, para tanto, propondo financiamento público por meio do FIES, inclusive, para a pós-graduação, também, pressupõem articulação com a Universidade Aberta do Brasil, para a qual, a prioridade é o ensino mediado pelas novas tecnologias de informação e comunicação, principalmente para formar os professores da educação básica em exercício da função.

É inegável, conforme aponta Gentilli em entrevista à Deuer (2014), que a ampliação das oportunidades de acesso é um componente fundamental para a educação, e, ao considerarmos que, em 2002, tínhamos aproximadamente três milhões e meio de estudantes no Ensino Superior e, hoje, estes chegam a cerca de oito milhões, apresentamos 
uma ampliação de acesso que possibilita inclusive às pessoas moradoras de comunidades mais remotas o acesso pela Universidade Aberta do Brasil.

Porém a garantia em lei não pode ser vista como progressão linear para a realidade social, pois há, nesse processo, uma dimensão de luta pela efetivação do direito reconhecido e garantido pela lei (CURY, 2002). A efetivação da educação como direito no Brasil perpassa, segundo Oliveira e Araújo (2005), por três embates: acesso, permanência e qualidade de ensino. O questionamento de Cury (2014) em relação à grande ampliação da oferta de vagas no Ensino Superior direciona-se ao seguinte fato: como toda essa oferta será fiscalizada? E questionamos, ainda, como fica o grande mote da universidade brasileira de valorização do tripé ensino-pesquisa-extensão?

Pensamos que o acesso ao Ensino Superior precisa estar garantido com qualidade, e essa pressupõe mais vagas nas universidades, e que essas, por sua vez, articulem ensinopesquisa-extensão. Nesse sentido, o grande desafio lançado ao Ensino Superior, atualmente, no Brasil, conforme nos faz refletir Cury (2014, p. 604), “[...] é o de ser contemporânea no âmbito da ciência e da tecnologia", visto que a formação não pode ficar restrita apenas ao caráter profissional, no sentido de inserção no mercado de trabalho, pois a pesquisa básica, aquela com caráter de crítica, e não de aplicabilidade, precisa estar presente na universidade. Corremos, se isso não se der, o risco de ampliar o acesso sem discutir a qualidade e formar técnicos, e não intelectuais no Ensino Superior brasileiro, que, afastados da reflexão própria da pesquisa básica, impõem menos oposição às questões postas pelo sistema desigual.

A complexa relação entre ensino, pesquisa e extensão no Brasil prejudica a qualidade de ensino, o que pode ser sintoma das relações entre Educação Superior, pesquisa e Estado que, de uma maneira geral, está enfraquecida, não só em âmbito nacional, conforme aponta Ball (2011a). Nesse sentido, o sucateamento da universidade pública e o grande incentivo ao ensino desvinculado da pesquisa e extensão no setor privado refletem a condição da realidade objetiva, sobre a qual, talvez, não tenhamos possibilidade de mudança, sem uma mudança social. Porém, em relação àquilo que podemos operar em uma mudança mais imediata, especificamente no tocante aos estudos em Política Educacional, é que queremos empreender alguns esforços como a seguir descritos.

Ball (2011a) aponta que a pesquisa científica é afetada pela relação entre Educação superior, pesquisa e Estado, o que, pelo contexto que discutimos anteriormente, fragiliza a pesquisa científica de uma maneira geral. Porém, para Ball (2011a), os estudos educacionais 
sofrem de uma questão bastante específica e que tem origem na utilização de linguagem utilitária que desconsidera, em muitos casos, os estudos de áreas próximas, como a sociologia, filosofia, psicologia.

Além disso, Ball (2011a) constata que há uma ausência de teoria nos estudos educacionais que implica deixar “[...] o pesquisador preso a ideias preconcebidas, não investigadas e imponderadas" (BALL, 2011a, p. 92). Nesse sentido, para Ball (2011a), o debate epistemológico ${ }^{4}$ nos estudos educacionais é urgente, pois:

\begin{abstract}
A teoria pode separar-nos das 'contingências que nos fazem ser o que somos; ela abre possibilidades de não mais continuarmos vendo, fazendo ou pensando o que nós vemos, fazemos ou pensamos' (Mahron, 1992, p. 122). A teoria é um veículo para 'pensar diferente', é uma arena para 'hipóteses audaciosas' e para 'análises provocantes'. A teoria é destrutiva, disruptiva e violenta. Oferece uma linguagem para o desafio e formas de pensamento diferentes das articuladas para nós pelos dominantes. Oferece uma linguagem rigorosa e irônica para além do contingente. $\mathrm{O}$ propósito da teoria é desfamiliarizar práticas e categorias vigentes para fazê-las parecer menos evidentes e necessárias, abrindo espaços para a invenção de novas formas de experiência. (BALL, 2011a, p. 93).
\end{abstract}

Portanto, com base em Ball (2011a), defendemos que os estudos educacionais não são neutros e, nesse sentido, o debate epistemológico está intimamente ligado aos problemas político-sociais. E, por isso, a escolha epistemológica é importante com o intuito de esclarecer ao leitor e ao próprio pesquisador de onde se fala e por que se fala.

Mas há um grande debate nas ciências sociais no sentido de refletir se é possível que a pesquisa politicamente comprometida seja compatível com o rigor acadêmico (GEWIRTZ; CRIBB, 2011). Porém,

[...] a ideia de que as ciências humanas - assim como os estudos educacionais - situam-se fora ou acima da agenda política de gerenciamento da população, ou que, de alguma forma, detêm um status neutro, incorporado em um racionalismo progressivo flutuante, é um pensamento débil e perigoso (BALL, 2011a, p. 89).

Sob tal perspectiva que Ball (2011b) afirma que a epistemologia dos estudos educacionais funciona politicamente e está relacionada com o gerenciamento dos problemas práticos, mas isso não significa que a epistemologia seja a própria prática, a discussão teórica é necessária para afastar pensamentos já cristalizados. 
Especificamente no campo acadêmico da política educacional, defendemos que, para o fortalecimento do campo, é importante conhecermos as várias epistemologias que o compõem para, dessa forma, possibilitar ao pesquisador escolhas teóricas e metodológicas relacionadas aos seus problemas de pesquisa, bem como que as escolhas possam ser realizadas conforme a necessidade de seus objetos de estudo, e não o contrário.

Mas não estamos, com isso, desconsiderando a teoria, pois a pesquisa em política educativa é sempre reativa e parasítica (BALL, 2011b), portanto, “[...] a teoria é importante para a pesquisa em outro sentido. A teoria provê a possibilidade de desidentificação - o efeito de trabalhar 'em e contra' prevalentes nas práticas de sujeição ideológicas [...]" (BALL, 2011b, p. 43-44). Por isso, defendemos que o estudo epistemológico em Política Educacional é importante para conhecermos as diferentes teorias e suas origens, suas bases e sua relação com a metodologia.

Ball e Mainardes (2011) apontam que, em decorrência do esforço de muitos pesquisadores, a literatura internacional é rica em modelos e abordagens para a pesquisa em Política Educacional, segundo diferentes perspectivas teóricas: marxismo, estruturalismo, pós-estruturalismo e pluralismo. E esses estudos em Política Educacional, em âmbito internacional, podem tomar três diferentes formas: “[...] a) o desenvolvimento de modelos analíticos através dos quais as políticas podem ser analisadas e interpretadas; b) análise de um conjunto de questões relacionadas às políticas; c) a análise crítica de políticas específicas [...]" (BALL; MAINARDES, 2011, p.11). Ball e Mainardes (2011) questionam em que medida as pesquisas no Brasil fazem relação com essa produção internacional, pois a característica dos estudos em Política Educacional no Brasil se compõe basicamente de dois grupos:

[...] a) estudos de natureza teórica sobre questões mais amplas do processo de formulação de políticas, abrangendo discussões sobre mudanças no papel do Estado, rede de influências no processo de formulação de políticas, abordagens históricas das políticas educacionais brasileiras (geralmente vinculadas à análise dos contextos socioeconômico e político), entre outros aspectos; b) análise e avaliação de programas e políticas educacionais específicas. (BALL; MAINARDES, 2011, p.12).

Esses dois “tipos” de pesquisa em Política Educacional no Brasil são fundamentais para o avanço do conhecimento no campo da Política Educacional, porém Mainardes (2009) questiona em que medida os estudos teóricos têm contribuído para as análises de políticas específicas e de que maneira os estudos de políticas específicas incorporam as questões teóricas. 


\section{CONCEPÇÕES DE ESTADO E POLÍTICA EDUCACIONAL: UM OLHAR SOBRE A PRODUÇÃO DO CONHECIMENTO A PARTIR DA CARTOGRAFIA SOCIAL}

Ao considerarmos que as teorias não são neutras, procuramos, neste trabalho, apresentar um mapeamento provisório das perspectivas analíticas explicitadas pelos pesquisadores e sua relação com o conceito de Estado e Política Educacional, por meio da Cartografia Social. Os mapas cartográficos são modos de imaginar e representar o espaço, pois a realidade tem muitas semelhanças com os mapas (SOUZA SANTOS, 1988).

Para que desempenhem bem sua função, Souza Santos (1988) destaca que os mapas precisam distorcer a realidade, pois não podem ser do "tamanho" dela, e por isso que desvirtuam a realidade por meio de três mecanismos: a escala, a projeção e a simbolização. Os mapas podem privilegiar a representação, os chamados mapa-imagem, ou a orientação, os mapas instrumentais. Por conta dessas características de inacabamento e representação da realidade em constante mutação, os mapas cartográficos são, também, formas de rejeição aos fundamentos da modernidade, assumindo um posicionamento pós-moderno ${ }^{5}$ (TELLO; GOROSTIAGA, 2009).

O posicionamento pós-moderno, em uma perspectiva pluralista, descarta a possibilidade de que exista uma única compreensão da realidade (TELLO; GOROSTIAGA, 2013); e, assim, conforme afirma Paulston (2001), a cartografia social contribui para representar as metáforas do debate plural e torna-se uma ferramenta espacial que possibilita visualizar a grande complexidade das perspectivas do conhecimento.

Nesse sentido, procuramos, em nossa pesquisa, reunir concepções distintas de Estado e Política Educacional que pudessem ser incompatíveis entre si. Isso posto, convidamos o leitor a olhar conosco esse mapa representativo das perspectivas analíticas dos pesquisadores em Política Educacional, procurando deixar de lado a busca incansável pela "melhor" teoria e abrindo espaço para o debate plural.

A meta-análise que realizamos buscou uma amostra representativa nas teses e dissertações dos Programas de Pós-Graduação em Educação no Estado do Paraná (20102012), na linha de pesquisa em Política Educacional, para comparar as perspectivas analíticas explicitadas pelos pesquisadores com as concepções que apresentam sobre Estado e Política Educacional. 
Nossa amostra foi selecionada a partir da explicitação, no resumo do trabalho, quanto à teoria utilizada pelo autor para realizar sua análise, pois esse foi nosso critério metodológico para estabelecer uma amostra. No decorrer da meta-análise, identificamos alguns apontamentos epistemológicos dos autores que nos auxiliaram a estabelecer nosso mapa representativo e provisório das epistemologias da Política Educacional, porém nem todos os pesquisadores apresentaram qual a base epistemológica de sua pesquisa, apesar de declararem a teoria utilizada para a análise.

Em nosso mapa, buscamos identificar, com a epistemologia, as teorias utilizadas, bem como os autores referentes citados pelos pesquisadores em suas análises e relacionados diretamente por eles às teorias utilizadas. Entretanto não temos a menor pretensão de fazer alguma classificação dos autores utilizados pelos pesquisadores, pois, como assinalam Tello e Mainardes (2012), uma perspectiva epistemológica não é sinalizada com apenas um autor, antes, sim, é trabalho de longo prazo fazer esse levantamento, pois existe uma grande carência desse tipo de mapeamento na América Latina, assim esse nosso mapeamento visa contribuir para as reflexões sobre as escolhas que fazemos em nossas análises sobre Política Educacional.

Figura 1 - Mapa das Epistemologias da Política Educacional e autores referentes

\section{MARXISMO (Marxi Frigotto; Kosik. Pochmann; Clavatta)}

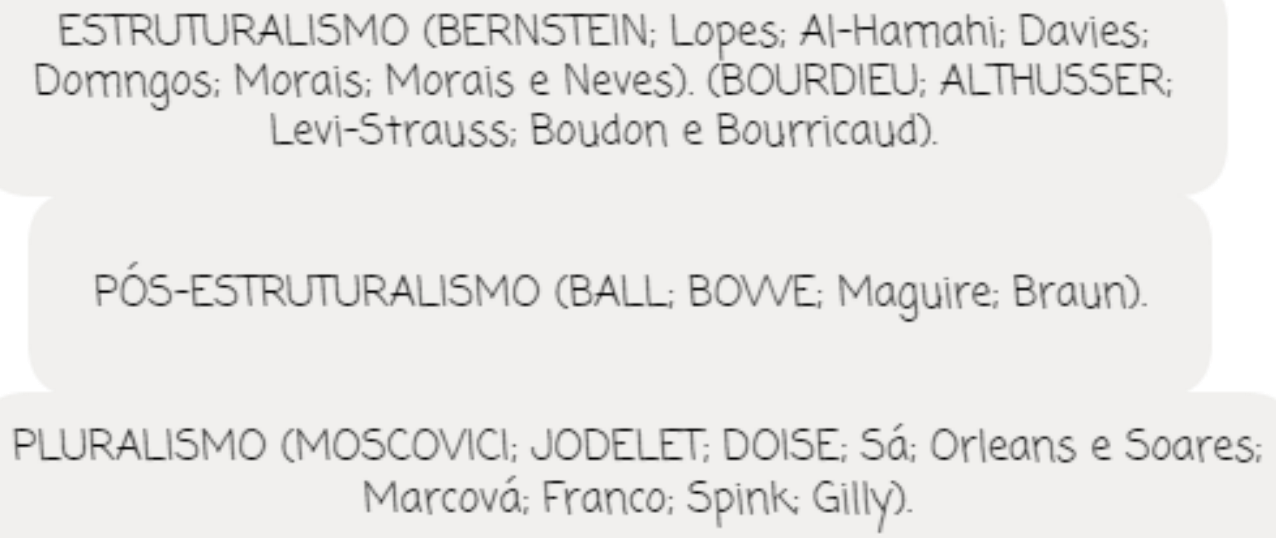

Fonte: Elaboração da autora. 
Identificamos que a epistemologia mais recorrente na amostra analisada foi o marxismo, que está em destaque em nosso mapa, porém houve espaços abertos para teorias de base estruturalistas como a "Recontextualização do Discurso de Bernstein" e a "Violência Simbólica em Bourdieu", pós-estruturalistas como o "Ciclo de Políticas de Ball" e de base pluralista como a "Teoria das Representações Sociais".

Nosso mapeamento buscou, ainda, comparar as perspectivas analíticas e as concepções de estado e Política Educacional apresentadas pelos autores. Percebemos que alguns pesquisadores separaram a discussão do conceito de Política Educacional e Estado da teoria utilizada como base para a discussão dos dados, o que dificultou identificar as relações entre perspectiva analítica, concepção de Estado e Política Educacional. Para nós, isso foi surpreendente, pois a linha de pesquisa analisada foi "Política Educacional" e percebemos que, em alguns trabalhos, a discussão sobre Estado e Política Educacional é apresentada como um "apêndice" da pesquisa, muito mais no formato de revisão da literatura. Nesse sentido, nem sempre ficou evidente a relação entre a teoria utilizada, a epistemologia e as concepções apresentadas nas análises, pois nem sempre houve preocupação dos autores com os conceitos utilizados e a relação teoria/epistemologia.

As pesquisas que apresentam uma perspectiva epistemológica marxista defendem um compromisso político em nome da classe trabalhadora para a transformação do real, isso pode ser explicado com base em Masson (2013), pelo fato de que postura, método e práxis são dimensões de uma mesma realidade no materialismo histórico-dialético. Em oposição ao idealismo, o materialismo histórico e dialético de Marx e Engels (1986) relaciona o surgimento da estrutura social, do Estado, das ideias e da linguagem ao trabalho, pois a vida determina a consciência, e não o contrário. Sob tal ótica, ficou claro, em nossa meta-análise, que, segundo uma perspectiva epistemológica marxista, é necessário compreender o papel do Estado moderno e suas transformações históricas, pois política pública é vista como a materialidade da intervenção do Estado (MASSON, 2013).

Já em relação às pesquisas que apresentam uma perspectiva epistemológica estruturalista, que tem como objetivo estudar as estruturas que caracterizam os traços inerentes do ser humano (THIRY-CHERQUES, 2006) e consideram o Estado e suas agências (ou aparelhos) como expressões máximas do poder capitalista que regula o discurso oficial, identificamos que as apropriações teórico-metodológicas para as análises em Política Educacional, a partir de uma perspectiva estruturalista, ficaram relacionadas à "Recontextualização do Discurso" em Bernstein e à "Violência Simbólica" em Bourdieu, com uma interpretação da política como exercício do monopólio da violência do Estado, 
porém, especificamente em relação à Política Educacional, consideram que pode ser recontextualizada de acordo com cada contexto educacional e agente que dela participe, assim mesmo, dentro de um sistema capitalista existe possibilidade de políticas emancipatórias e inclusivas

Como representativo da perspectiva epistemológica pós-estruturalista, que, segundo explicam Mainardes, Ferreira e Tello (2011), aponta para a importância de analisarmos o discurso das políticas, identificamos em nossa meta-análise o "Ciclo de Políticas" de Ball (analisa o contexto de influência, produção de texto e contexto da prática). Porém outras apropriações teórico-metodológicas são possíveis: a) análise de contextos, textos e consequências (Taylor); b) Modelo baseado na análise de discurso (Fulcher). Todas essas apropriações da perspectiva pós-estruturalista pressupõem disputas e embates dos diferentes sujeitos envolvidos nas políticas (MAINARDES; FERREIRA; TELLO, 2011). Nessa perspectiva, os sujeitos são dotados de voz, e as políticas surgem de determinações de várias origens, podendo ser texto e discurso e estar ancorada em um campo de lutas e poder (MAINARDES, 2013).

$\mathrm{Na}$ representação da perspectiva epistemológica pluralista, em nossa amostra, as representações sociais tiveram destaque. É importante destacar que a Teoria das Representações Sociais considera necessário explicar os fenômenos que envolvem o homem de uma forma coletiva sem perder de vista suas características individuais. Mainardes, Ferreira e Tello (2011) explicam que a perspectiva pluralista aborda a política como uma arena na qual transitam a pluralidade dos atores envolvidos por diversas causas e visões do mundo. Para os pluralistas, existem diferentes focos de poder, e o Estado é apenas mais um dos que participa de um todo que não é articulado, assim, consideram a lógica das políticas governamentais como um grande jogo definido por causas complexas. Algumas apropriações da perspectiva pluralista são possíveis: a) análise de políticas e programas (Cochran); b) análise cognitiva de políticas (Muller); c) Cartografia Social (Paulston). Essas apropriações impõem a necessidade de o pesquisador buscar compreender as implicações das abordagens que empregam por conta da possibilidade do relativismo da multiplicidade de fatores (MAINARDES; FERREIRA, TELLO, 2011).

No âmbito da discussão da produção do conhecimento em Política Educacional, percebemos que, assim como apontam Mainardes (2013) e Tello (2013), a definição de "epistemologias" no plural é necessária, pois existem diferentes perspectivas, posicionamentos e enfoques epistemológicos possíveis de ser aplicados nas pesquisas em Política Educacional (MAINARDES, 2013; TELLO, 2013). Tello (2012) destaca que a 
perspectiva epistemológica é a cosmovisão que o pesquisador assume, como, por exemplo: marxismo, neomarxismo, estruturalismo, pós-estruturalismo, existencialismo, humanismo, positivismo e pluralismo. Em nossa amostra, o marxismo, estruturalismo, pósestruturalismo e pluralismo tiveram representatividade, porém não foram citados diretamente pelos pesquisadores na maioria das pesquisas.

O posicionamento epistemológico, que é a apresentação de uma teoria vinculada ao campo de estudo, pode se converter em posicionamento político. Em nossa amostra, identificamos a teoria do "Ciclo de Políticas" de Ball como a única voltada especificamente para o campo de estudo da Política Educacional. E isso chamou bastante nossa atenção porque ainda carecemos de teorias específicas para as análises em Política Educacional.

Já o enfoque epistemológico que define a metodologia de pesquisa, o que Tello (2012) convencionou chamar de "epistemetodologia", que está relacionado tanto à perspectiva como ao posicionamento epistemológico, foi apresentado em alguns trabalhos mais pontualmente, mas na maioria dos trabalhos tal aspecto não ficou explícito, e sim subentendido a partir da teoria utilizada para a análise. Nesse sentido, a preocupação em apontar a teoria utilizada apareceu nos trabalhos analisados, porém a relação epistemologia/teoria foi pouco explícita.

Portanto, pensamos que o debate epistemológico no campo de estudo da Política Educacional no Brasil é urgente e necessário, pois tendo mais clareza entre epistemologia, teoria e análise de dados, poderemos ambicionar dados mais profícuos para essas análises.

\section{CONSIDERAÇÕES FINAIS}

Esperamos que este nosso mapeamento provisório das epistemologias da Política Educacional nos auxilie a refletir no tocante às mudanças palpáveis que queremos para a pesquisa básica no Ensino Superior brasileiro, pois acreditamos que podemos travar uma luta ideológica por meio da qualidade de nossas pesquisas em Política Educacional. Qualidade relacionada ao compromisso ideológico ligado ao rigor acadêmico, à fidedignidade dos dados e à vigilância epistemológica ${ }^{6}$. Pensamos que pesquisa politicamente comprometida é sim compatível com rigor acadêmico.

No entanto, consideramos que a pesquisa em Política Educacional depende de expressões mais veementes sobre as concepções de Política Educacional e Estado e sua relação com a teoria ou epistemologia adotada pelo pesquisador, pois de que forma a 
epistemologia e os conceitos que deixamos de explicitar poderia fortalecer nosso campo de estudos e pesquisas?

\section{REFERÊNCIAS}

BALL, S. J. Intelectuais ou técnicos? O papel indispensável da teoria nos estudos educacionais. In: BALL, S. J.; MAINARDES, J. (Orgs.). Políticas educacionais: questões e dilemas. São Paulo: Cortez, 2011a. p. 78-99.

BALL, S. J. Sociologia das políticas educacionais e pesquisa crítico-social: uma revisão pessoal das políticas educacionais e da pesquisa em política educacional. In: BALL, S. J.; MAINARDES, J. (Orgs.). Políticas educacionais: questões e dilemas. São Paulo: Cortez, 2011b. p.21-53.

BALL, S. J.; MAINARDES, J. Introdução. In: (Orgs.). Políticas educacionais: questões e dilemas. São Paulo: Cortez, 2011.p. 11-18.

\section{CAPES. Portal Eletrônico da Coordenação de aperfeiçoamento de Pessoal de Nível}

Superior. Disponível em:

$<$ http://conteudoweb.capes.gov.br/conteudoweb/ProjetoRelacaoCursosServlet?acao=pesquisarAr ea\&identificador $=38>$. Acesso em: 10 fev. 2015.

CURY, C. R. J. Direito à educação: direito à igualdade, direito à diferença. Cadernos de Pesquisa, n. 116, p. 245-262, jul. 2002.

CURY, C. R. J. Formação e conhecimento: perspectivas filosóficas e sociológicas. Avaliação, v. 19, n. 3, p. 603-629, nov. 2014.

DUER, C. and D'Alessandre Vanesa. Conversacion con Pablo Gentili: La evaluación de la calidad educativa em América Latina: modelos emancipadores em construcción, Diálogos del SITEAL, nov. 2014. Disponível em: http://www.siteal.org/sites/default/files/siteal dialogo gentili.pdf.

GEWIRTZ, S.; CRIBB, A. O que fazer a respeito de valores na pesquisa social: o caso da reflexividade ética na Sociologia da Educação In: BALL, S. J.; MAINARDES, J. (Orgs.). Políticas educacionais: questões e dilemas. São Paulo: Cortez, 2011a.

JAPIASSÚ, H; MARCONDES, D. Dicionário Básico de Filosofia. Jorge Zahar Editor: Rio de Janeiro, 2001.

MAINARDES, J. Análise de políticas educacionais: breves considerações teórico-metodológicas. Contapontos. vol. 9, n. 1, p. 4-16, jan./abr 2009.

MAINARDES, J. Las epistemologias de la política educativa y sus contribuciones para el campo. In: TELLO, C. (Coord.). Epistemologias de la política educativa: posicionamentos, perspectivas y enfoques. Campinas/SP: Mercado de Letras, 2013.

MAINARDES, J.; FERREIRA, M. S.; TELLO, C. Análise de políticas: fundamentos e principais debates teórico-metodológicos. In: BALL, S.; MAINARDES, J. (Orgs.). Políticas Educacionais: questões e dilemas. São Paulo: Cortez, 2011. p. 143-172. 
MARX, K. e ENGELS, F. A ideologia alemã. São Paulo: Editor Hucitec, 1986.

MASSON, G. Orientações para o desenvolvimento de investigação em políticas educativas a partir da teoria marxista. In: ALMEIDA, M. L. P. de; TELLO, C. (Orgs.). Estudos epistemológicos no campo da pesquisa em política educacional. Campinas/SP: Mercado das Letras, 2013. p. 55-76.

FERREIRA, E. B.; OLIVEIRA, D. A. Apresentação. In: FERREIRA, E. B.; OLIVEIRA, D. A. (orgs.) Crise da escola e políticas educativas. Belo Horizonte: Autêntica Editora, 2009.

OLIVEIRA, R. P. de; ARAUJO, G. C. de. Qualidade do ensino: uma nova dimensão da luta pelo direito à educação. Revista Brasileira de Educação, Rio de Janeiro, n.28, abr. 2005. Disponível em

http://www.scielo.br/scielo.php?script=sci_arttext\&pid=S141324782005000100002\&lng=pt\&nrm =isso Acesso em 30 jul. 2013 http://dx.doi.org/10.1590/S1413-24782005000100002.

PAULSTON, R. Mapeando a educação comparada depois da pós-modernidade. Educação, Sociedade e Cultura, n. 16, p.203-239, 2001. Disponível em: $<$ http://www.fpce.up.pt/ciie/revistaesc/ESC16/16-arquivo.pdf> $>$. Acesso em: 25 jan. 2015.

SAVIANI, D. O estado e a promiscuidade entre o público e o privado na história da educação brasileira. In: . (Org.). Estado e políticas educacionais na história da educação brasileira. Vitória, ES: Edufes, 2010, p. 17- 44.

SILVA, T. T. da. Documentos de Identidade: uma introdução às teorias do currículo. Belo Horizonte: Autêntica, 2005.

SOUZA SANTOS, B de. Uma cartografia simbólica das representações sociais: prolegómenos a uma concepção pós-moderna do direito. Revista Critica de Ciências Sociais, n. 24, p. 139-172, mar. 1988. Disponível em:

$<$ http://www.ces.uc.pt/myces/UserFiles/livros/94_Cartografia\%20simbolica_RCCS24.pdf $>$.

Acesso em: set. 2014

TELLO, C. El campo teórico de la política educacional: modelos, abordajes y objetos de estúdio. Jornal de políticas educacionais, n. 14, p. 62-75, jul./dez. 2013. Disponível em: <file:///C:/Users/hp/Downloads/38225-141289-1-PB\%20(1).pdf>. Acesso em: jan. 2015.

TELLO, C. Las epistemologías de La política educativa: vigilância y posicionamento epistemológico Del investigador em política educativa. Práxis Educativa, v. 7, n.1, p. 53-68, jan./jun. 2012.

TELLO, C.; GOROSTIAGA, J. M. Aportes da cartografia social para uma epistemetodologia do visual na pesquisa sobre política educativa. In: TELLO, C.; ALMEIDA, M. L. P. (Orgs.).

Epistemologias de la política educativa: posicionamentos, perspectivas y enfoques. Campinas/SP: Mercado das Letras, 2013.

TELLO, C.; GOROSTIAGA, J. M. El enfoque de la cartografia social para el análisis de debates sobre políticas educativas. Práxis Educativa, v. 4, n. 2, pp. 159-168, jul./dez. 2009.

TELLO, C.; MAINARDES, J. La posición epistemológica de los investigadores en Política Educativa: Debates teóricos en torno a las perspectivas neomarxista, pluralista y pos-estructuralista. Archivos Analíticos de Políticas Educativas/Education Policy Analysis Archives, v. 20, n. 9, 
p.1 -31, 20 mar. 2012. Disponível em: <file:///C:/Users/hp/Downloads/988-2394-1-PB.pdf>. Acesso em: ago. 2013.

THIRY-CHERQUES, H. R. O primeiro estruturalismo: método de pesquisa para as Ciências da Gestão. RAC, v. 10, n. 2, p. 137 - 156, abr./jun. 2006.

\footnotetext{
${ }^{1}$ Por perspectiva analítica entendemos aqui a teoria utilizada pelo pesquisador para fazer a análise de dados.

${ }^{2}$ Para chegar em nosso grupo representativo, separamos, por meio dos títulos, das 216 teses e dissertações defendidas entre 2010-2012, na linha de pesquisa "Política Educacional", os trabalhos específicos sobre Política Educacional, pois as linhas se conjugam com a história e a gestão educacional em sua composição. Das 91 teses e dissertações selecionadas pelos títulos, escolhemos uma amostra de 50\%+1 para a análise dos resumos, no sentido de identificar as perspectivas analíticas que aparecem enunciadas explicitamente nos resumos das teses e dissertações. Descobrimos nessa amostra um total de 13 trabalhos em que os pesquisadores explicitam em seus resumos as perspectivas analíticas, assim, apresentaremos algumas das principais teorias que compõem o debate teórico-metodológico para as pesquisas em política educacional a partir dessa amostra, e que podem trazer reflexões mais amplas para a pesquisa em Política Educacional no Brasil.
}

3 Meta-análise ou metaciência inclui o estudo da lógica e da epistemologia da ciência (BOURDIEU, CHAMBOREDON, PASSERON, 2015).

${ }^{4}$ Epistemologia é entendida aqui como disciplina que toma as ciências como objeto de investigação a partir da crítica ao conhecimento científico, e estudo da filosofia e história das ciências (JAPIASSÚ; MARCONDES, 2001)

${ }^{5} \mathrm{O}$ pós-modernismo reserva um de seus ataques ao sujeito racional, livre, autônomo, centrado e soberano da modernidade e inclina-se para a incerteza e a dúvida, desse modo, desconfiando profundamente das certezas e das afirmações categóricas (SILVA, 2005). A condição pós-moderna, segundo Paulston (2001), é reflexiva, valorizando o "eu", o espaço e a multiplicidade e tem como base cinco teses principais: a) rejeição aos fundamentos do iluminismo, presentes principalmente nas narrativas do progresso, emancipação e razão; b) rejeição ao conhecimento universal e hegemônico, destacando a necessidade de um pluralismo antihegemônico; c) visão de que todas as pretensões de conhecimento são problemáticas; d) ataque ao eurocentrismo, valorizando as experiências pós-coloniais; e) reorientação da pesquisa: do tempo ao espaço, dos fatos para as interpretações, da verificação de proposições e narrativas para o mapeamento da diferença.

${ }^{6}$ Termo utilizado por Bourdieu, Chamboredon e Passeron (2015) para problematizar a responsabilidade de cada pesquisador em explicitar e estudar a epistemologia utilizada em sua pesquisa. 